\title{
GESTÃO ESCOLAR DEMOCRÁTICA E QUALIDADE DE ENSINO: ESTUDO DE CASO EM UMA ESCOLA MUNICIPAL NO INTERIOR DE SÃO PAULO \\ http://dx.doi.org/10.5902/2318133825367
}

\author{
Alessandra Teresinha de Oliveira \\ Universidade Federal de São Carlos, Brasil. \\ Glauco Henrique de Sousa Mendes \\ Universidade Federal de São Carlos, Brasil. \\ Raquel Ottani Boriolo \\ Universidade Federal de São Carlos, Brasil.
}

\begin{abstract}
Resumo
Neste artigo discutem-se os impactos que o perfil do gestor escolar e a adoção da gestão democrática na escola têm na qualidade do ensino, mensurada de forma indireta a partir do desempenho da escola em avaliações externas de larga escala. Para isso, foram sistematizadas evidências desses impactos a partir da literatura de referência e da condução de um estudo de caso em uma escola municipal de pequeno porte, num município do interior do Estado de São Paulo, levantando-se dados oficiais do desempenho da escola no Ideb entre 2007 a 2013, o estilo de gestão adotada nesse período e entrevistas com dois de seus gestores. As evidências apontam que o tempo de permanência do diretor numa mesma escola é determinante para os resultados alcançados no Ideb, junto com a participação da comunidade escolar e o estilo democrático da gestão, sendo a escola estudada um retrato dos impactos desses fatores.

Palavras-chave: gestão democrática, qualidade de ensino, gestão escolar, Ideb.
\end{abstract}

\section{DEMOCRATIC SCHOOL MANAGEMENT AND EDUCATION QUALITY: A CASE STUDY AT A MUNICIPAL SCHOOL IN THE INTERIOR OF SÃO PAULO}

\section{Abstract}

This article discusses the impacts of the school manager profile and the adoption of the democratic management style have in the quality of education, measured indirectly from the performance of the school in large-scale external evaluations. For this, evidence of these impacts was systematized from the reference literature, and a case study was conducted in a small school in a municipality in the interior of the State of São Paulo, using official data on school performance from Ideb, between 2007 and 2013, the style of management adopted in this period and interviews with two of its managers. Evidence indicates that the director's length of stay in the same school is decisive for the results achieved in Ideb, along with the participation of the school community and the democratic style of management, being the school studied a picture of the impacts of these factors.

Key-words: democratic management, education quality, school management, Ideb. 


\section{Introdução}

I gestão pública é uma área voltada ao planejamento, elaboração, implementação, monitoramento, avaliação e coordenação de ações relativas a programas e políticas públicas, incluindo o estudo de estratégias para diagnosticar e resolver problemas existentes nas diversas esferas da administração pública, tanto direta, quanto indireta (Santos, 2012).

Nessa linha de pensamento discute-se neste texto a gestão democrática e sua influência na qualidade do ensino. Busca-se observar de que maneira o perfil dos gestores públicos e da sua atuação no âmbito da educação influencia a qualidade do processo educativo. Mais diretamente interessa observar o impacto que a gestão democrática e o perfil dos diretores de escolas públicas têm nos resultados alcançados por essas escolas em avaliações nacionais de desempenho externas de larga escala, como a Prova Brasil e o Saeb.

De acordo com Pereda e Lucchesi (2015) há diversas pesquisas que se dedicam a explicar o desempenho das escolas em provas de larga escala e uma das mais recentes relaciona o desempenho de escolas públicas ao perfil de seus diretores. Segundo as autoras, "o perfil do gestor escolhido é mais relevante/determinante para o alcance de resultados educacionais do que a forma de seleção adotada" (p. 1). O estudo demonstra que, em termos de perfil do gestor, a experiência, medida pelo tempo de permanência na direção da escola, é uma das variáveis centrais. Assim, o desempenho dos alunos das redes municipais e estaduais é melhor nas escolas em que os diretores permanecem de cinco a quinze anos no cargo. Outro fator que as autoras destacam como gerador de impacto no desempenho da escola nessas avaliações é o papel da gestão no incentivo à formação continuada dos seus profissionais.

A importância do diretor de escola na qualidade do ensino está na centralidade de seu papel gestor enquanto aquele que tem uma visão geral da instituição e que pode integrar as questões burocráticas à parte pedagógica. $O$ estilo de gestão parece ser fundamental para compreender os resultados alcançados pela escola (Riscal, 2016).

No que se refere à dimensão da gestão democrática o interesse é compreender em que medida a forma de participação das famílias, dos alunos, dos professores, diretores, e de toda a comunidade nas atividades e decisões da escola influencia o desempenho. Um dos aspectos centrais na concepção de gestão democrática é a existência e o formato dos conselhos escolares. Segundo Oliveira (2010) quanto mais participativo é o processo deliberativo nas escolas, quanto maior e mais efetiva a participação desses diversos atores no processo decisório, via conselhos escolares, por exemplo, maiores são as chances de aprendizado e, consequentemente, melhores resultados se esperam dos alunos dessas escolas nas avaliações externas de larga escala.

Nessa perspectiva surge o problema central abordado aqui: de que forma o perfil do gestor escolar e a adoção da gestão democrática na escola impactam na qualidade do ensino, considerando uma medida indireta de qualidade do ensino, mensurada a partir do desempenho das escolas em avaliações externas de larga escala? 
A discussão proposta avalia, em última instância, se e em que medida o sucesso ou o fracasso de uma unidade escolar pode ser influenciado pela gestão escolar e pelo estilo de gestão adotado pelo diretor, argumentando-se que não são apenas as características ligadas ao corpo docente e discente que influenciam a qualidade do aprendizado, refletido e concretizado nos resultados alcançados nessas avaliações.

Para realizar essa discussão o artigo baseia-se num estudo de caso de uma escola pública de um município de pequeno porte no interior do Estado de São Paulo, valendo-se da série histórica dos resultados por ela obtidos no Ideb no período de 2007 à 2013, da observação do estilo de gestão adotada nesse período, considerando a forma e o tempo de investidura dos diretores no cargo e estilo de gestão adotada, verificando a existência e funcionamento do Conselho Escolar, assim como da realização de entrevistas com dois de seus gestores, o primeiro que permaneceu na escola por dez anos e o segundo que está no cargo há três anos.

O foco das entrevistas foi verificar a percepção que esses gestores têm acerca da relação entre o tempo de permanência em uma unidade escolar e os resultados alcançados em termos de desempenho da escola nas provas, além de abordar sua percepção com relação ao papel que a gestão democrática tem no desempenho escolar.

Busca-se com esse estudo de caso dialogar com os principais achados das pesquisas nacionais que apontam a centralidade da gestão escolar democrática e do perfil do gestor escolar nos resultados alcançados pelas escolas nas avaliações de larga escala. Dessa forma, o intuito é contribuir com a discussão sobre a adequação dos modelos atuais de gestão escolar, dando subsídios para que as escolas localizadas em municípios de pequeno porte se organizem e consigam obter melhores resultados.

\section{Qualidade de ensino e gestão escolar: discussão teórica e normativa}

Uma vez posto o objetivo de discutir em que medida a qualidade de ensino de uma escola pode ser influenciada pela gestão escolar e pelo estilo de gestão adotada e não apenas por características ligadas ao corpo docente e discente, é fundamental definirmos os conceitos centrais que norteiam essa discussão. Assim, apresenta-se aqui o entendimento adotado para os conceitos de gestão democrática, qualidade de ensino e as formas de mensurar a qualidade de ensino, assim como referencia-se resultados de pesquisas atuais que vêm demonstrando o papel determinante da gestão e dos gestores na melhoria da qualidade do ensino nas escolas, via seu desempenho em provas de larga escala.

Para esse entendimento o embasamento são os documentos normativos que regem a educação básica no Brasil, que são a Constituição Federal de 1988, a LDB e o PNE. No que se refere à gestão democrática a Constituição Brasileira de 1988 apresenta no artigo 206 os princípios em que o ensino deve ser ministrado e a gestão democrática do ensino público aparece no item VI, da seguinte forma:

Art. 206 - O ensino será ministrado com base nos seguintes princípios: I igualdade de condições para o acesso e permanência na escola; II liberdade de aprender, ensinar, pesquisar e divulgar o pensamento, a arte e o saber; III - pluralismo de ideias e de concepções pedagógicas, e coexistência de instituições públicas e privadas de ensino; IV - gratuidade do ensino público em estabelecimentos oficiais; V - valorização dos profissionais do ensino, garantido, na forma da lei, plano de carreira para o 
magistério público, com piso salarial profissional e ingresso exclusivamente por concurso público de provas e títulos, assegurado regime jurídico único para todas as instituições mantidas pela União; VI - gestão democrática do ensino público, na forma da lei; VII - garantia de padrão de qualidade; VIII piso salarial profissional nacional para os profissionais da educação escolar pública, nos termos de lei federal. (Brasil, 1988)

A LDB, por sua vez, apresenta em seu artigo 14 dois princípios da gestão democrática, que são a participação dos profissionais da educação na elaboração do projeto político-pedagógico e a participação da comunidade escolar nos conselhos escolares.

Segundo Oliveira, Moraes e Dourado (2008) a gestão democrática tem como característica a participação efetiva de todos os membros envolvidos no processo de ensino e aprendizagem - pais, professores, estudantes e funcionários - nos diversos processos realizados na escola, desde o planejamento de projetos até a administração dos recursos da escola. Segundo os autores,

numa escola pautada em uma gestão democrática a forma de administrar a educação constitui-se num fazer coletivo, permanentemente em processo, processo que é mudança contínua e continuada, mudança que está baseada nos paradigmas emergentes da nova sociedade do conhecimento, os quais, por sua vez, fundamentam a concepção de qualidade na educação e definem, também, a finalidade da escola. (Oliveira; Moraes; Dourado, 2008, p. 3)

Pela consulta aos documentos normativos percebe-se que a expectativa é que uma educação pautada por uma gestão democrática gera a melhoria da qualidade do ensino (Brasil, 1996). Mas na prática, para verificar-se como isso ocorre no cotidiano educacional, são aplicadas avaliações que aferem a qualidade da educação nacional e a partir dos resultados é possível traçar um panorama de como está a educação em nosso país.

O Inep, o órgão responsável por elaborar e aplicar as avaliações nacionais de larga escala, tem utilizado como principais indicadores de desempenho as taxas de aprovação e as notas médias obtidas nos exames, que combinados dão origem ao Índice de Desenvolvimento da Educação Básica - Ideb:

O Ideb foi criado pelo Inep em 2007, em uma escala de zero a dez. Sintetiza dois conceitos igualmente importantes para a qualidade da educação: aprovação e média de desempenho dos estudantes em língua portuguesa e matemática. A série histórica de resultados do ldeb se inicia em 2005, a partir de onde foram estabelecidas metas bienais de qualidade a serem atingidas não apenas pelo País, mas também por escolas, municípios e unidades da Federação. A lógica é a de que cada instância evolua de forma a contribuir, em conjunto, para que o Brasil atinja o patamar educacional da média dos países da OCDE. Em termos numéricos, isso significa progredir da média nacional 3,8, registrada em 2005 na primeira fase do ensino fundamental, para um Ideb igual a 6,0 em 2022, ano do bicentenário da Independência. (Brasil, 2007) 
O Ideb é um dos principais parâmetros empregados no PNE (2014-2024) para traçar as metas de qualidade para a educação brasileira. Esse plano traz vinte metas, sendo que sua sétima meta, que visa a melhoria do desempenho da qualidade da educação, estipula como objetivo a ser alcançado nacionalmente, até o ano de 2024, a obtenção de nota 6.0 no Ideb por todas as escolas.

Um estudo realizado pela Fundação Itaú Social (2015) mostrou que a atuação do diretor na unidade escolar tem bastante influência sobre o desempenho dos alunos. Lemos no estudo que o tempo de permanência do gestor no cargo, assim como seu estilo de gestão, sobretudo seu incentivo à formação continuada do corpo docente, são fatores cruciais para uma melhor qualidade de ensino:

Algumas características do diretor estão sistematicamente relacionas à
maior aprendizagem dos alunos, dentre as quais destacam-se:
Permanecer no cargo de diretor na mesma escola pelo período de 5 a 15
anos; Incentivar/promover a formação continuada de professores; Possuir
formação de magistério. Em geral, diretores indicados (politicamente, por
técnicos ou outras indicações) permanecem menos tempo nas escolas(o
que é negativo para o desempenho dos alunos). Em geral, diretores
indicados politicamente incentivam menos a formação continuada dos seus
professores (o que é negativo para o desempenho dos alunos). Diretores
indicados politicamente são mais propensos a possuir a formação de
magistério do que diretores selecionados de outras maneiras(o que é
positivo para o desempenho dos alunos).O conjunto de análises realizadas
evidencia que diferentes processos de seleção recrutam diretores com
qualificações diferentes e, por essa via, impactam rendimento e
aprendizagem (Pereda; Lucchesi, 2015, p. 6).

Outra pesquisa que se dedicou à compreensão da influência da gestão na qualidade do ensino foi a de Riscal (2016). O autor realizou um levantamento sistemático da literatura de referência, identificando os principais indicadores para a qualidade de ensino, e utilizou-os num modelo de análise para estimar seu impacto na explicação do desempenho das escolas públicas brasileiras no Ideb. O objetivo da sua pesquisa foi avaliar quantitativamente o impacto da gestão democrática no desempenho nacional das escolas públicas em avaliações externas e de larga escala, utilizando como referência os resultados do Ideb 2013.

Riscal (2016) analisou como a presença e o funcionamento de conselhos escolares, a existência, a forma de elaboração do projeto político-pedagógico e o perfil do diretor de escola - atentando-se à sua formação, à forma como esse profissional ingressou no cargo e seu tempo de permanência na escola - ajudam a explicar as notas obtidas pelas escolas no Ideb. O autor também considerou o efeito desempenhado por outras variáveis presentes no Censo Escolar e na Prova Brasil, como da localização geográfica da escola, e o perfil socioeconômico dos alunos, além da presença de computadores e laboratórios nessas escolas. Ou seja, Riscal (2016) buscou controlar o efeito do perfil dos diretores e da gestão democrática a partir do perfil dos discentes e da estrutura da própria escola, elementos usualmente apontados como os mais importantes no desempenho das escolas em índices como o ldeb. 
Como conclusão, Riscal (2016) identificou que as escolas com as maiores notas no Ideb 2013 são aquelas que elaboraram seu PPP democraticamente, ou seja, com a participação da comunidade escolar e do conselho escolar, aquelas nas quais o conselho escolar teve a participação de pais de alunos e se reuniu mensalmente. Nessas escolas também foram observadas reuniões do Conselho de Classe.

O autor aponta, ainda, que outras variáveis como participação do conselho escolar nas decisões sobre aplicação de recursos financeiros, localização geográfica da escola, assim como sua realidade socioeconômica, incentivo à formação continuada do corpo docente, entre outros fatores, exercem impacto positivo no resultado do Ideb.

Apesar de observar que todos esses fatores influenciam o Ideb, Riscal (2016) encontra evidências de que o perfil do diretor, em termos de formação, experiência e tempo de atuação, é a variável que exerce maior peso na explicação do desempenho das escolas no Ideb. Se o diretor ingressa na carreira a partir de concurso público, permanece acima de cinco anos na mesma escola, dedica-se exclusivamente a ela e interage com a comunidade escolar, isso resulta em uma contribuição maior para a melhoria do Ideb do que a contribuição verificada pelo desempenho dos demais indicadores.

\section{Estudo de caso}

Partindo das pesquisas de escala nacional conduzidas por Riscal (2016) e Pereda e Lucchesi (2015), que relacionaram o perfil do gestor escolar e da adoção da gestão democrática na escola à qualidade do ensino - mensurada de forma indireta a partir do desempenho das escolas em avaliações externas de larga escala -, a proposta desse estudo foi investigar se e como tais elementos se apresentam em uma escola de pequeno porte num município do interior paulista, observando também se e como são percebidos e levados em conta pela gestão nessa localidade.

A metodologia utilizada foi a de estudo de caso, empregando técnicas de entrevista qualitativa e levantamento de dados secundários como fonte de informações.

A escola, localizada em um município do interior de São Paulo, na região administrativa de Araraquara, possuía, de acordo com o Censo 2010, 10.414 habitantes, tendo uma economia basicamente agrícola. Nesse município existem oito escolas, sendo uma particular, com os níveis infantil, fundamental e médio, e sete instituições públicas, cobrindo todos os níveis de ensino. As escolas públicas estão distribuídas da seguinte forma: três escolas municipais de educação infantil, três escolas municipais de ensino fundamental I e II, e uma escola estadual que têm os segmentos fundamental II e ensino médio.

O estudo de caso foi conduzido em uma escola municipal de ensino fundamental I, que tem, aproximadamente, quinhentos alunos matriculados e funciona nos períodos matutino, e vespertino, oferecendo no período noturno aulas da educação de jovens e adultos.

O interesse em observar essa escola é que ela teve como gestora durante dez anos uma diretora de carreira, alçada à posição via concurso público, e essa gestora foi substituída por uma diretora indicada politicamente. Com isso, existe a possibilidade de observar se há percepções e desempenho dos dados dada a mudança da forma de ingresso no cargo. 
Após a saída da diretora de carreira outras duas ocuparam o cargo de direção antes da diretora atual, que se encontra no cargo há três anos. Foram entrevistadas a diretora concursada e a atual. Uma vez que houve essa mudança de perfil na gestão, o interesse estava em observar, entre outros fatores, se as gestoras apresentam percepções diferentes acerca do papel da gestão democrática no desempenho escolar.

O foco são as séries iniciais, do $1^{\circ}$ ao $5^{\circ}$ anos, já que o ldeb está dividido entre escolas das séries iniciais e finais do ensino fundamental. Os dados do Ideb foram levantados nas últimas quatro avaliações, cobrindo os períodos das duas gestões de interesse.

Para as entrevistas foi elaborado um roteiro estruturado, no sentido de verificar, junto à atual gestora da escola, suas percepções em relação à qualidade de ensino, os resultados da escola nessas avaliações e o seu papel enquanto gestora, assim como trabalhar suas percepções acerca da gestão democrática do ensino. O mesmo roteiro foi aplicado à diretora de carreira, que ficou por uma década no cargo, para ter-se um parâmetro de comparação.

É importante pontuar que inicialmente a ideia era realizar as entrevistas e gravá-las, mas ambas as entrevistadas solicitaram responder às perguntas via formulário escrito. Assim, encaminhou-se por e-mail para cada uma delas cerca de vinte questões, abordando seu perfil: formação, tempo de experiência na escola pesquisada, forma de investidura no cargo de direção, carga horária na escola, incentivo de realização de formação continuada dos docentes e seu estilo de gestão, etc.; o perfil da escola: elaboração do projeto político-pedagógico, existência e atuação do Conselho de Classe e Conselho Escolar, existência e tipo de eventos que integrem comunidade e escola, etc.; a visão e percepção que têm acerca do papel do gestor da escola, sua visão sobre o que é e como funciona a gestão democrática e quais as atitudes que consideram fundamentais para uma gestão ser considerada democrática, além de indagar sobre suas atitudes e expectativas acerca do seu papel para a qualidade do ensino e o desempenho da escola no ldeb.

Na sequência são apresentados os resultados da pesquisa, concluindo-se o artigo com as principais contribuições trazidas para compreender a importância da gestão na esfera educacional no sentido de obtenção de melhoria na qualidade do ensino.

\section{Resultados}

A escola pesquisada foi municipalizada no ano de 2000 e nela anualmente funcionam vinte salas no período matutino e vespertino e a EJA no período noturno.

São vinte professores efetivos, um professor para cada área do conhecimento - Arte, Educação Física e Língua Estrangeira - e quatro professores auxiliares que substituem os que prestam serviços nos cargos em comissão.

Em 2000, ano da municipalização, a equipe gestora era formada pela diretora, vicediretora e pela coordenadora pedagógica. A diretora era servidora do Estado e permaneceu no cargo mesmo após as eleições municipais de 2000. Já a vice-diretora e a coordenadora pedagógica, que eram professoras do quadro, foram substituídas pela prefeitura. Essa diretora permaneceu na gestão durante dez anos, de 1999 até 2009. Sua formação inicial é em Pedagogia, com especialização em Psicopedagogia, Gestão Escolar, Didática e Educação Especial. 
Observando o desempenho da escola no Ideb no período de atuação dessa diretora percebe-se uma boa qualidade do ensino, pois nos períodos de 2007 e de 2009 a escola atingiu, nas avaliações de larga escala, a meta projetada, igualando-se à nota estadual e superando a média nacional.

No ano de 2010, em decorrência de novas eleições municipais, houve a substituição da diretora, assumindo uma nova direção. A diretora nomeada permaneceu no cargo apenas no ano de 2010. Sua sucessora, também em cargo de comissão, atuou na escola nos anos de 2011 e 2012. Nesse período, observando o Ideb, percebe-se que a escola apresentou uma queda em seu desempenho, não atingindo a meta projetada, ficando abaixo da média do Estado, mas mantendo uma nota maior que a média nacional.

Em 2013 a escola passou novamente por mudanças em sua gestão, devido às eleições municipais. A gestora que assumiu a escola em 2013, atual gestora, é formada em Letras/Inglês, Arte e Gestão Escolar.

O Ideb em 2013 subiu, porém, não atingiu a meta projetada. Novamente o que ocorre é que a escola fica abaixo da média estadual e acima da nacional.

Essa movimentação do Ideb entre as gestões é compatível com o apresentado pela literatura acerca da dificuldade de executar um bom trabalho de gestão numa situação de rotatividade e pouca permanência do gestor na escola e da possibilidade de descontinuidade do trabalho. As próprias diretoras entrevistadas reconhecem a centralidade do tempo de permanência para efetivarem um bom trabalho:

"A permanência do diretor na escola é importante para criar laços com a comunidade escolar. Os alunos precisam sentir um "pertencimento". Os projetos têm continuidade e todos ganham. Quanto mais o diretor fica na escola, mais ele tem oportunidade de influenciar positivamente a todos". (Depoimento em entrevista, diretora anterior)

"Até mesmo por que conhece melhor seus professores, seus alunos, o clima organizacional tende a ser mais satisfatório quando o diretor tem seus princípios bem definidos, portanto, gera melhor controle sobre o processo de ensino". (Depoimento em entrevista, diretora atual) 
Gráfico 1 -

Resultados do Ideb para Brasil, Estado de São Paulo, Município e Escola pesquisada, nos anos de 2007, 2009, 2011 e 2013.

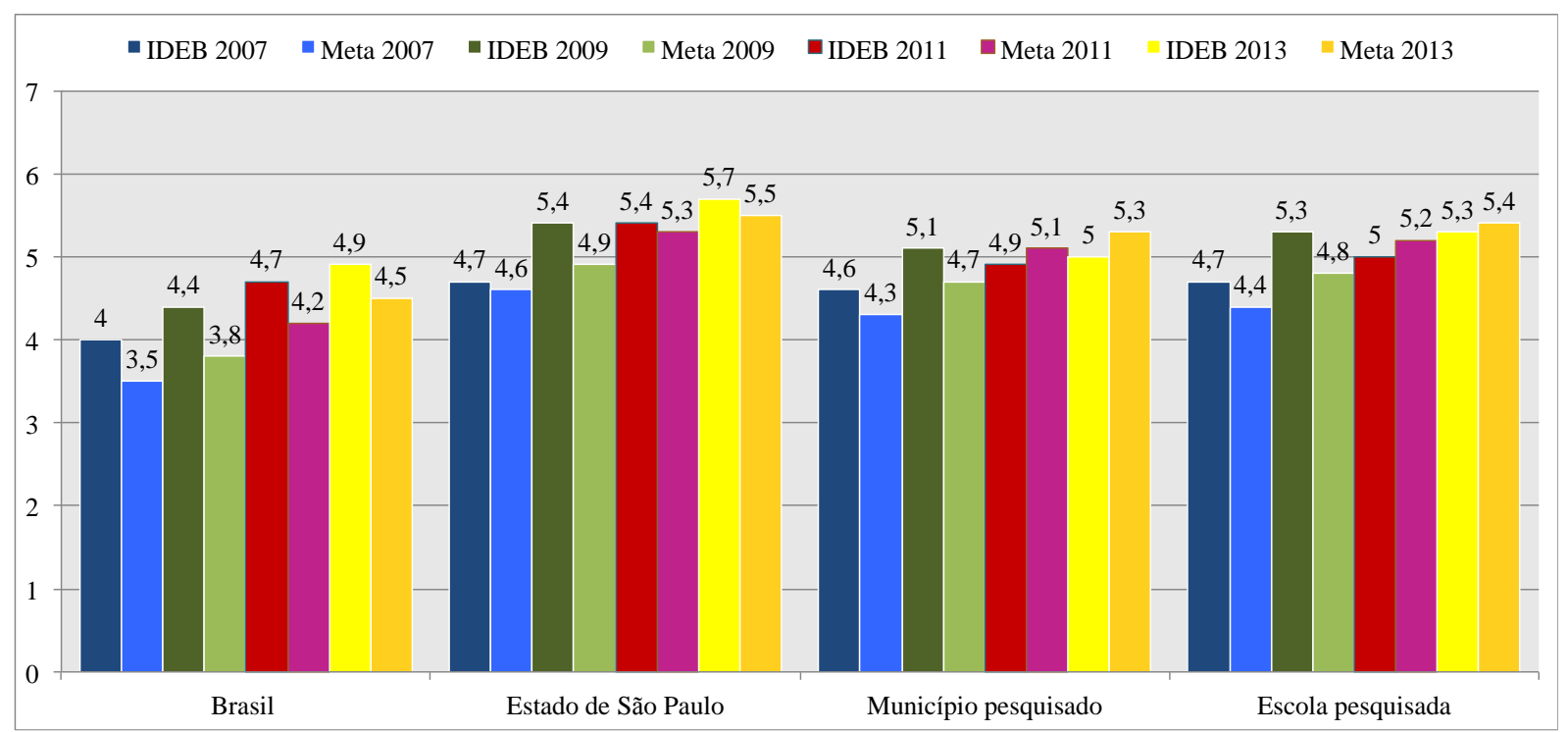

Fonte: Inep.

Ao serem indagadas diretamente sobre como percebem a relação entre tempo de permanência de um gestor na escola e desempenho da escola nos resultados do Ideb, ambas as gestoras afirmaram que sim, esse tempo importa para os resultados, sobretudo porquê permite melhorar o relacionamento interno da equipe.

A diretora afirmou que com a proximidade criam-se laços de pertencimento também com os professores e, dessa forma, conseguem dialogar construtivamente para compartilhar objetivos. Enfatizou que o tempo de permanência faz com que haja negociação e estabelecimento de metas compartilhadas e facilita cobranças em torno dessas metas, na medida em que todos podem se unir em busca de um mesmo objetivo. Permanecendo por mais tempo é possível cobrar com mais eficácia a equipe:

"Como o diretor conhece muito bem sua equipe, por assim dizer, ele assume a postura de 'cobrança' construtiva, isto é, passa a estimular, mais do que isso, apoiar seus educadores na busca de diversidade de formas de ensino para conseguir o resultado esperado, já que usa da psicologia ao dizer 'vistam a camisa' e expõe que se houver sucesso, haverá o reconhecimento, mas se houver fracasso é porque todos, em algum momento, falharam". (Depoimento em entrevista, diretora atual)

Os resultados do Ideb, em conjunto com as manifestações das diretoras, são fortes indícios para se considerar que a permanência do diretor na escola é um fator essencial para a qualidade de ensino, sendo centrais para criar laços de pertencimento com a comunidade, como ressaltado por uma das diretoras entrevistadas. Quanto maior o tempo de permanência do diretor na escola, maior a oportunidade de conhecer o perfil de toda a comunidade escolar, como ressaltado pela atual diretora, e negociar metas com maior propriedade. 
As ponderações das entrevistadas permitem visualizar, também, a consciência que têm acerca do papel do gestor, da sua missão na escola e da importância de se pensar enquanto gestor de pessoas e não administrador de recursos simplesmente, transparecendo em suas concepções uma visão mais humanista de gestão, destacando o aspecto democrático da atuação:

"O diretor tem papel democrático, é líder que leva seus liderados a crescerem e superarem seu líder. A missão é ensinar e aprender." (Depoimento em entrevista, diretora anterior)

"Na minha opinião o gestor tem um papel importantíssimo. Por ser o eixo principal para que a escola se desenvolva, assim sendo, cabe a ele o papel não só de organizar, mas também supervisionar, dinamizar, articular e o principal de todos, estimular para que todos os envolvidos com a educação: escola, família e sociedade, busquem juntos o melhor caminho para a qualidade do processo ensino-aprendizagem." (Depoimento em entrevista, diretora atual)

A concepção de gestão democrática que essas diretoras têm passa fundamentalmente pela perspectiva dialógica. A diretora anterior afirmou, por exemplo, que para ser democrática uma gestão precisa, necessariamente, ouvir a todos os envolvidos na comunidade escolar. A diretora atual ressaltou que não basta estar no papel que a gestão precisa adotar o estilo democrático, afirmando ser necessário incorporar na prática os aspectos dessa democratização. E ao ser indagada acerca de quais seriam esses aspectos destacou que

"Na minha opinião as principais atitudes para uma gestão ser democrática necessita ter a efetiva participação da comunidade escolar, para que isso ocorra os membros que a compõem precisam conhecer as leis, as propostas governamentais e as concepções da escola e que estejam, acima de tudo, engajados a obterem uma escola democrática." (Depoimento em entrevista, diretora atual)

Um fator importante a se observar é que há uma diferença de percepção da atuação do Conselho Escolar entre as duas gestoras, o que leva a pensar na hipótese de que o tempo de permanência do gestor na escola pode também afetar esse funcionamento, característica fundamental do processo de gestão democrática. Verificase que na perspectiva da diretora que permaneceu uma década no cargo, a diretora concursada, o conselho escolar funcionava bem, se reunia regularmente e participava da gestão. Já na perspectiva da gestora atual, que está há menos tempo no cargo, há relatos da dificuldade de funcionamento e da integração com a comunidade. Ela percebe obstáculos à participação, distanciamento e timidez da comunidade em se apropriar desse instrumento. Não foram coletados dados suficientes para afirmarmos essa correlação, mas é um indício a ser futuramente investigado.

Por fim, cabe destacar a percepção dessas gestoras acerca do trabalho da gestão voltado aos resultados nas provas externas. Ambas as entrevistadas pontuaram ser essa uma preocupação central da gestão, uma vez que os resultados alcançados permitiriam fazer um acompanhamento sistemático dos avanços no aprendizado. Segundo a concepção da diretora anterior, a prova permite, a partir dos resultados alcançados, uma "visão geral para futuras intervenções, partindo do que o aluno sabe e abrir horizontes" 
(depoimento em entrevista, diretora anterior), ou seja, a avaliação externa forneceria um diagnóstico para se definir onde estão as fraquezas e as forças da escola e priorizar os conteúdos a serem trabalhados. Reconhece, assim, o potencial dessas avaliações para o estabelecimento de metas e o acompanhamento do desempenho ao longo do tempo.

A diretora atual também aponta a preocupação com os resultados, mas difere da perspectiva da diretora anterior ao afirmar que a escola não deve "pautar seu plano de ensino somente na busca de melhoria do Ideb" (Depoimento em entrevista, diretora atuaç), sendo preciso levar em conta uma série de outras necessidades e outros objetivos da educação. Assim, podemos levantar a hipótese de que a preocupação e dedicação que cada gestor dá aos resultados da escola nas avaliações externas, pode influenciar o trabalho feito em sala de aula visando essas provas, o que também impactaria nos resultados alcançados pela escola.

Perguntadas acerca do que elas acreditam que contribuiria para melhorar os resultados da escola no Ideb as diretoras apontaram, via de regra, o perfil e o trabalho docente como fatores essenciais. Uma das diretoras apontou que a permanência de professores na escola é fundamental para o bom desempenho nas provas, pois conhecendo melhor o contexto da escola e o perfil de seus alunos o professor pode também sentir-se mais próximo e trabalhar melhor as especificidades dos alunos dessa escola, e com isso contribuir para a melhoria da qualidade do ensino. A outra enfatizou as práticas de planejamento como centrais para o êxito:

"Há fatores externos e internos que contribuem "para os resultados positivos/negativos. A pouca rotatividade dos professores é de extrema importância no desenvolvimento intelectual, cognitivo e afetivo dos alunos". (Depoimento em entrevista, diretora anterior)

"São vários os fatores que impactam nos resultados obtidos, mas ganha ênfase a maneira do processo de ensino ser planejado, isto é, os indicadores passam a ser incorporados como indicadores de conhecimento da real necessidade, ou seja, se transformam em norteadores para os planejamentos dos educadores que passam a debater, refletir e reorganizar suas práticas pedagógicas." (Depoimento em entrevista, diretora atual)

\section{Considerações finais}

A pesquisa realizada buscou identificar se e de que forma o perfil do gestor escolar e a adoção da gestão democrática na escola impactariam na qualidade do ensino, mensurada de forma indireta a partir do desempenho das escolas em avaliações externas de larga escala, utilizando como metodologia o estudo de caso uma escola de pequeno porte em um município do interior de São Paulo.

Evidenciou-se, com a sistematização da literatura, que o tempo de permanência de um mesmo diretor na escola é variável central para a obtenção de resultados positivos no Ideb e essas evidências ajudam a entender a variação verificada no desempenho da escola estudada entre 2007 e 2013 nesse indicador, ou seja, no momento em que houve maior permanência de uma mesma gestora, que ficou por dez anos na escola, observou- 
se uma melhoria no desempenho, sempre atingindo as metas e estando equivalente ao desempenho do Estado. No momento em que houve maior rotatividade na gestão foi quando houve encolhimento no indicador, que voltou a crescer na sequência, mas ficando, ainda, abaixo da meta e do Estado.

Além dos dados do desempenho escolar o estudo retratou as percepções das gestoras dessa escola no que concerne a gestão democrática e o desempenho da escola nas provas de larga escala. A partir das entrevistas realizadas percebeu-se que ambas as diretoras são conscientes de seu papel enquanto gestoras, percebem que sua permanência em uma mesma escola possibilita a realização de um trabalho mais organizado, pois além de conhecerem a sua equipe, conhecem a realidade da clientela atendida pela escola e com isso podem seguir um plano de trabalho que vislumbre atingir o objetivo principal da educação que é formar cidadãos preparados para atuarem de forma mais consciente em nossa sociedade. Há, nas manifestações de ambas as gestoras, uma valorização do diálogo, como essencial à gestão democrática.

Embora ambas as gestoras compartilhem uma mesma visão acerca do seu papel e da importância da gestão democrática, elas demonstraram visões um pouco diferentes acerca da centralidade dos resultados obtidos pelo ldeb como um guia para 0 planejamento das atividades pedagógicas. Não está no escopo desse estudo explicar em que medida essa diferença de percepções impacta nos resultados obtidos pela escola, nem mesmo qual a direção da relação, mas essa observação permite formular a hipótese de que gestores que se movem pelos resultados no ldeb tendem a trabalhar em prol da obtenção desses resultados e, com isso, tendem a obter resultados melhores do que aqueles que valorizam menos esses resultados.

A principal conclusão desse estudo indica que o gestor desempenha papel fundamental para a qualidade do ensino, medida aqui de forma indireta pelo desempenho da escola no Ideb, e pontuar que mesmo em escolas de pequeno porte, semelhantes a estudada, a figura do diretor é central, que importa o tempo em que ele permanece à frente do planejamento e da gestão escolar. O gestor que passa mais tempo em um mesmo ambiente escolar tem melhores condições de conhecer os docentes, os técnicos, os alunos e os familiares e criar um clima de maior envolvimento e pertencimento de grupo.

\section{Referências}

BRASIL. Constituição da República Federativa do Brasil. Brasília: Senado, 1988. Disponível em <http://www.planalto.gov.br/ccivil 03Constituicao/Constituicao.htm>. Acesso em 12 abril 2016.

BRASIL. Instituto Nacional de Pesquisas Educacionais Anísio Teixeira. IDEB Resultados e Metas, 2007. Disponível em <http://ideb.inep.gov.br>. Acesso em 12 março 2016.

BRASIL. Lei n. 9.394, 20 de dezembro, 1996. Disponível em <http://www.planalto.gov.br/ ccivil 03/Leis/L9394.htm>. Acesso em 9 dez. 2015.

OLIVEIRA, João Ferreira de; MORAES, Karine Nunes de; DOURADO, Luiz Fernandes. Gestão escolar democrática: definições, princípios e mecanismos de implementação. Disponível

$<$ http://www.escoladegestores.mec.gov.br/site/4sala politica gestao escolar/ pdf/texto2_1.pdf>. Acesso em 8 dez. 2015. 
OLIVEIRA, Radígia. Gestão democrática na educação. Disponível em $<$ http://www.unicef.org/ brazil/pt/RPINovembro2010.pdf>. Acesso em 4 dez. 2015.

PEREDA, Paula; LUCCHESI Andrea. Avaliação econômica: o processo de seleção de diretores nas escolas públicas brasileiras. Disponível em < http://www.redeitausocialdeavaliacao.org.br/wpcontent/uploads/2015/11/sintese sel.direto res 20151117.pdf>. Acesso em 6 dez. 2015.

RISCAL, José Reinaldo. Mapeamento quantitativo dos impactos da gestão democrática no desempenho das escolas públicas no ldeb 2013-2016. São Carlos: UFSCas, 2016. 240f. Dissertação (mestrado em Educação). Centro de Educação e Ciências Humanas, Universidade Federal de São Carlos.

SANTOS, Maria Paula Gomes dos. O estado e os problemas contemporâneos. Florianópolis: UFSC, 2012.

Alessandra Teresinha de Oliveira é pós-graduada em Gestão Pública pela UFSCar e graduada em Pedagogia.

Endereço: Av. Campos Sales, 234 - 14830-000 - Rincão - SP - Brasil.

E-mail: allettepp@gmail.com.

Glauco Henrique de Sousa Mendes é doutor em Engenharia de Produção pela Universidade Federal de São Carlos e professor no Departamento de Engenharia de Produção da UFSCar.

Endereço: Rod. Washington Luís, km 235 - caixa postal 676 - 13565-905 - São Carlos - SP - Brasil.

E-mail: glauco@dep.ufscar.br.

Raquel Ottani Boriolo é pós-graduada em Gestão Organizacional e Recursos Humanos pela UFSCar e graduada em Administração.

Endereço: Rod. Washington Luís, Km 235 - 13565-905 - São Carlos - SP - Brasil.

E-mail: tutoria.ufscar.raquel@gmail.com.

Recebido em 18 de outubro de 2016.

Aceito em 30 de março de 2017. 